\title{
Public Emotional Response on the Black Lives Matter Movement in the Summer of 2020 as Analyzed Through Twitter
}

\author{
Laura Patnaude ${ }^{1}$, Carolina Vásquez Lomakina ${ }^{1}$, Akshat Patel $^{1} \&$ Gulhan Bizel $^{1}$ \\ ${ }^{1}$ Frank J. Guarini School of Business, Saint Peter's University, Jersey City, New Jersey \\ Correspondence: Dr. Gulhan Bizel, Frank J. Guarini School of Business, Saint Peter's University, 2641 John. F. \\ Kennedy Blvd, Jersey City, New Jersey, US. E-mail: gulhanvb@gmail.com
}

Received: January 20, $2021 \quad$ Accepted: February 24, $2020 \quad$ Online Published: February 27, 2021

doi:10.5539/ijms.v13n1p69 URL: https://doi.org/10.5539/ijms.v13n1p69

\begin{abstract}
The rapid growth of social media platforms and mobile technology presents the opportunity to analyze the sentiments Tweets express. For this paper, Twitter will be the focus of study related to Black Lives Matter throughout the summer of 2020. In addition, the language and sentiment at that particular time are evaluated to uncover public opinion and track how it changed throughout a season. Although a tweet may be classified as positive or negative, there are key terms and tones used with both classifications. By understanding what makes a tweet positive or negative, the root of public opinion can be identified.
\end{abstract}

Keywords: Analyze, Black Lives Matter, BLM, mobile, public opinion, sentiment, social media, Summer 2020, Twitter

\section{Introduction}

Black Lives Matter (BLM) is a movement formed to protest against racially motivated violence against black people was born from the hashtag, \#BlackLivesMatter. Since its inception, the movement has sparked conversations across the world both in person and via social media on the treatment of black people in America and the systems of racism currently in place. Overall, the movement and related organizations typically advocate against police violence against black people as well as various policy changes considered to be related to black liberation.

Anti-black racism in the United States continues to be a problem since the abolition of Jim Crow laws which enforced segregation between black and white Americans in public places over half a century ago (Haffner M., 2018, p. 1258). Black Americans continue to receive discriminatory treatment from law enforcement officials and face major obstacles in securing housing, health care, and quality education, as well as experiencing irregularities in the justice system. In response, the black community has formed different movements to request justice and equal treatment for every citizen of color.

One such movement is BLM that emerged in 2013. In response to the acquittal of George Zimmerman for the shooting of 17-year-old Trayvon Martin on February 26, 2012, a black community organizer made a post on Facebook discussing her views on the situation. After that initial post, people replied with "\#BlackLivesMatter" which went viral, turned into a rallying cry, and generated a campaign against racism and discrimination (Wijers, Lavrijssen, Chateau, \& Visser, 2017).

The accumulation of different inequitable events, mostly of police brutality that occurred before 2012, made \#BlackLivesMatter represent all the black lives that were lost unfairly. In response, \#AllLivesMatter began to appear at almost the same time as Black Lives Matter on social media. It grew in popularity, but it was often used to counter the Black Lives Matter movement. Although some had good intentions using \#AllLivesMatter, it was that during that time people wanted to focus on black lives (Wijers et al., 2017). Although the message \#BlackLivesMatter may have been jarring to some and was seen as being exclusive when so many other groups were also discriminated against, the intention was never to say that one group was more deserving than another. It was that black lives were in danger despite perceived progress in racial disparities. The BLM movement redefines equality; to be equal does not just mean to be equal by law but to be treated equally by society and to be given the same chances (Wijers et al., 2017). 
BLM is a rallying cry against police brutality and systematic racism. Per BLM, the movement is an "ideological and political intervention in a world where black lives are systematically and intentionally targeted for demise" (Garza, 2018). The problem also revolves around the inadequate adoption of multiculturalism and racial inequality faced by a certain section of society. Understanding which terms are associated with BLM on social media and the associated tone, allows the public to understand why each side feels a certain way on the issue and better understand proposed solutions.

Social media has played a vital role in shaping the growth of the movement drastically. Social media has made it so that one thought that is shared on the internet can grow and change into something much larger. "....social media as a scaling tool that simultaneously facilitates strengthening the movement by facilitating collective meaning-making and the creation of support networks and expanding the movement" (Mundt, Ross \& Burnett, 2018 , p. 1). Social media creates a space where one idea can turn into much more and allows for people to organize and take action in a matter of clicks.

Social media has also taken ideas and turned them into events. In the beginning, these events were meetups. Perhaps a group of people were interested in the same television show and decided to host watch parties (Mundt et al., 2018, p. 7). In that same breath, social media made it so people of the same political ideologies could get together and make their voices heard. "...social media creates participation opportunities-such as boosting protest turnout or supporting fundraising campaigns - that broaden mobilization, thus helping scale movement endeavors (Mundt et al., 2018, p. 1-2). A simple idea could grow and be scaled up into a larger social movement in a matter of clicks.

The use of hashtags on social media has largely been successful in projecting the voices of oppressed groups and starting political movements (Haffner, 2018, p. 1258). It opens the door to gain perspectives from different groups of people who each have a unique perspective based on their life experiences. By clicking on a hashtag, one can read through statements on both sides of an issue or can focus on one side to delve into that perspective.

When looking through the lens of BLM, it was clear how social media was going to be how the movement took hold. Black Americans have been consistently active on Twitter creating the "...the cohesive, yet complex, community surrounding 'Black Twitter'" (Haffner, 2018, p. 1258). Before the birth of the BLM movement, there was already an online community where black Americans could share their thoughts and experiences. The acquittal of George Zimmerman, who shot and killed 17-year-old Trayvon Martin in 2012, sparked the birth of the \#BlackLivesMatter movement, raising awareness about racial injustice and police brutality (Haffner, 2018, p. 1258). Coupling the power of social media, along with engaged social media users on "Black Twitter", and the shocking event it was clear that the \#BlackLivesMatter message would amount to being larger than its 16-character hashtag.

BLM has deep ties to social media. The conversation all began from the simple hashtag "\#BlackLivesMatter" and has spurred protests against inequality and violence, international conversation, and several pieces of legislation. Since the movement's infancy, public opinion has ebbed and flowed. While companies like the NFL and NASCAR have shown their support and received positive feedback that encouraged the public to get involved, those companies also received a significant amount of backlash (Buchanan, Bui, \& Patel, 2020). Some national companies took opposite positions on BLM apparel with Starbucks and Whole Foods prohibiting employees from wearing pins, shirts, or other items indicating their support for racial justice while working (Lardieri, 2020).

After its emergence into society, debates on Twitter ensued using both \#BlackLivesMatter and its antithesis, \#AllLivesMatter. The discussions often became heated since both sides felt that they had a stronger argument that was the correct take. "These often-heated exchanges on social media also reveal the emergence of a few dominant ideological positions, emphasizing how different groups viewing the same media coverage interpret issues of race and police violence in dramatically different ways" (Carney, 2016, p. 182). While everyone had access to the same news stories, the reactions were incredibly different. Some felt that these events showed just how deep racism permeated the country while others felt that there were gross overreactions.

On May 25, 2020, George Floyd, a 46-year-old African American man, died after being handcuffed and pinned to the ground by a white police officer's knee (The New York Times, 2020). Police were called to the scene after Floyd purchased a pack of cigarettes with a counterfeit $\$ 20$ bill. The police found Floyd sitting on the hood of a car and appeared to be under the influence according to the officers. Floyd was ordered to step away from the car and, according to the police statement, "...he physically resisted officers. Officers were able to get the suspect into handcuffs and noted he appeared to be suffering medical distress" (The New York Times, 2020). Officers ultimately got Floyd into the police car. 
At 8:19 p.m., Officer Derek Chauvin pulled Floyd out of the passenger side of the car leaving Floyd face down on the ground with handcuffs still on (The New York Times, 2020). During this exchange, Chauvin lodged his left knee into Floyd's head and neck for seven minutes and 42 seconds while Floyd continued to say he could not breathe. This incident was caught on video. At 9:25 p.m., Floyd was declared dead (BBC News, 2020).

Once the footage of Officer Chauvin and George Floyd reached social media, it spread like wildfire. According to data collected by the Social Media Analytics Center at the University of Connecticut, in the 30 days since Floyd died, the incident was mentioned more than 80 million times across Twitter, Facebook, Reddit, and blogs (Beckman, 2020). On May 28, 2020, there were 8.8 million uses of \#BlackLivesMatter as national and global protests spread (Pew Research Center, 2020). People on both sides of the issue had strong opinions about the events and were sharing their opinions via social media or out in the streets during protests.

Based on an analysis made by the Pew Research Center, spikes can be seen since the first use of \#BlackLivesMatter but George Floyd's death skyrocketed statistics. After the circulation of a bystander's video of George Floyd's death, massive demonstrations occurred in cities throughout the United States and across the globe. This included hundreds of thousands of people in over 60 countries like England, Italy, Australia, Brazil, and Japan to go to the streets and show solidarity (Anderson, Barthel, Perrin, \& Vogel, 2020).

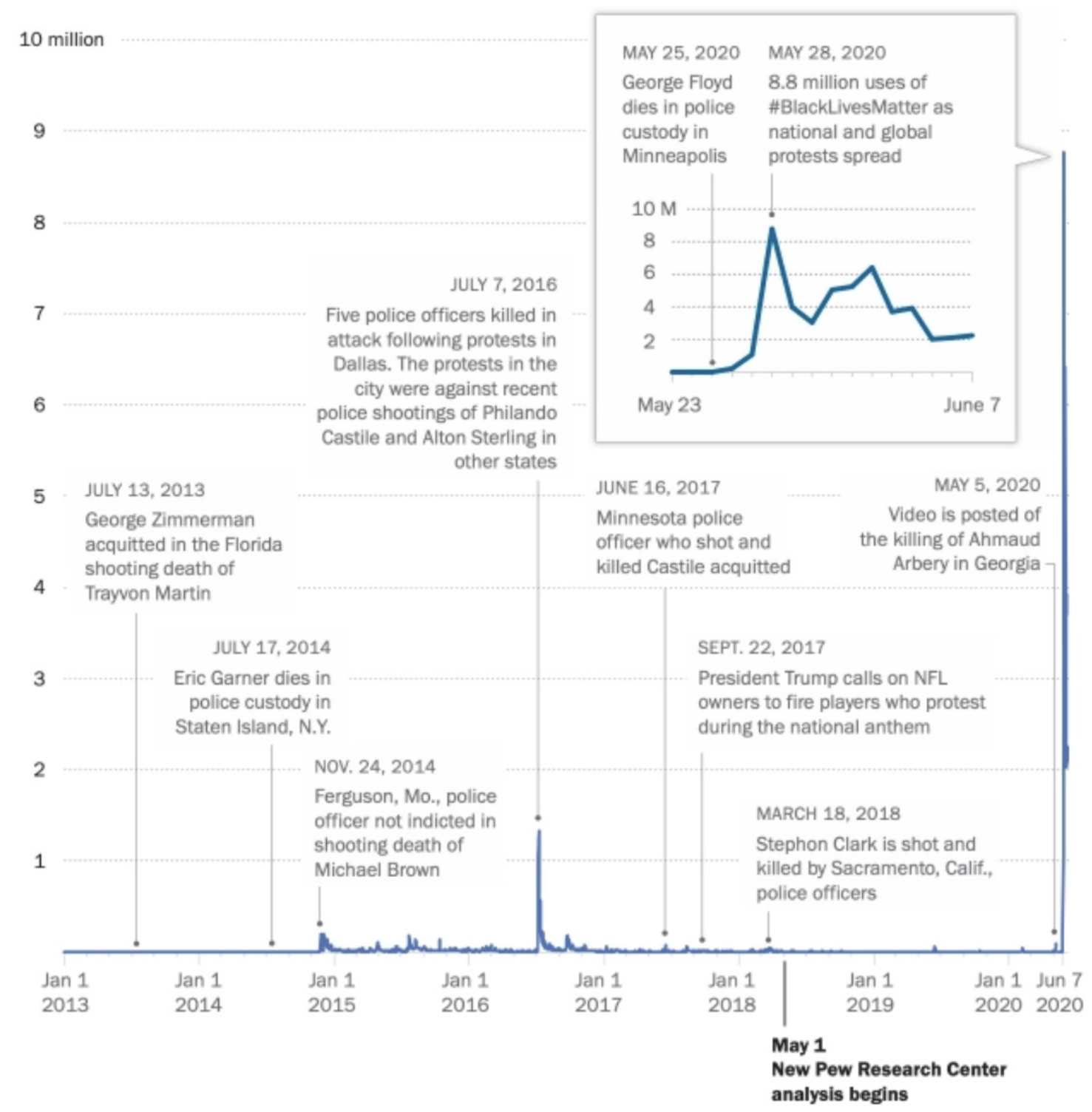

Figure 1. Pew research data

Source: Pew Research Center analysis of publicly available tweets using Crimson Hexagon. Data for Jan. 1, 2013-May 1, 2018 collected in June 2018; data for May 1, 2018-June 7, 2020 collected in June 2020. 
For the 30 days following the death of George Floyd, \#BlackLivesMatter was a trending topic and had been mentioned more than 80 million times on Twitter, Facebook, Reddit, and blogs, according to data collected by the Social Media Analytics Center at the University of Connecticut. The outrage was not limited to social media. BLM protests were the most searched item in the United States in Google history and commanded an immense amount of news coverage in early June (Pew Research Center, 2020).

In addition to George Floyd, there were several other calls for justice. In March 2020 Breonna Taylor, a Black medical worker was shot and killed by Louisville police officers during a raid on her apartment (Oppel, Taylor \& Bogel-Burroughs, 2020). When this story was picked up in the news, it became one of the main drivers of protests and demonstrations in summer 2020 over police brutality and racial injustice in the United States (Oppel et al., 2020). Another major story during this time that made waves on social media was Jacob Blake, a 29-year-old Black man who was left partially paralyzed after a police officer shot him seven times in the back outside an apartment complex in Kenosha, Wisconsin on August 23, 2020 (Morales, 2020). The shooting was captured on video by Blake's neighbor and was shared widely and rapidly on social media.

These events led to a call to defund the police. Different from disbanding the police, the call for defunding was made on the idea that the money allotted to police departments could be put towards other resources like social services for mental health, domestic violence, and homelessness (Andrew, 2020). Then, departments could be replaced with a community-based public safety model.

In addition to the events regarding Floyd, Taylor, Blake, and defunding the police, it is important to note the political divide in the United States at that time. Studies conducted by the Pew Research Center leading into 2020, “...illustrate the increasingly stark disagreement between Democrats and Republicans on the economy, racial justice, climate change, law enforcement, international engagement and a long list of other issues. The 2020 presidential election further highlighted these deep-seated divides. Supporters of Biden and Donald Trump believe the differences between them are about more than just politics and policies" (Dimock \& Wike, 2020). Beliefs on either side were strong and both were so stark in their black and white. One example is seen in tweets by prominent American political figures. In the days after Floyd's death, United States President Donald Trump tweeted, “"These THUGS are dishonoring the memory of George Floyd, and I won't let that happen,'... 'Just spoke to Governor Tim Walz and told him that the Military is with him all the way. Any difficulty and we will assume control but, when the looting starts, the shooting starts. Thank you!"” (The New York Times, 2020). On the other side of the political spectrum, then-presidential candidate Joe Biden tweeted, "'George Floyd deserved better and his family deserves justice,' Mr. Biden tweeted on May 26. 'His life mattered'" (The New York Times, 2020).

\section{Method}

Sentiment analysis of Twitter data was done using R statistical programming language to quantitatively analyze tweets related to the reaction to George Floyd's death and address its political consequences. Twitter data was used to complete sentiment analysis with a focus on text data wrangling, visualization, and interpretation. Sentiment analysis is a way of measuring a user's emotion on social media. This adds context to the message's meaning by measuring the tone of a conversation, comment, or mention. Positive sentiment refers to users being enthusiastic, happy, or excited while negative refers to users who are angry, annoyed, or frustrated.

Each word was considered a token to track the frequency of each word, create visualizations, and interpret the sentiment through the overall tweet. Having specific sentiment lexicons in a tidy format provided a standardized way to link the structure of the dataset with its meaning. Lexicons categorize words into a positive or negative flag as well as into emotions like anger, disgust, fear, joy, or using a score, with negative scores indicating negative sentiment.

Using Twitter data scraped from June 2020 to August 2020 of people in the United States, data was divided into 6 subsets. Assigning the numbers 1 and 2 to the month of June, 3 and 4 to the month of July, and 5 and 6 to the month of August. For the sentiment analysis, there were stop words or, words filtered out before processing. The defined stop words were "t.co", "csun", "blm", "rt", "https", "BLM", "blacklivesmatter", "black", "2", “\#blm", "\#blacklivesmatter", "august", and "georgefloyd" so those would not appear in the frequency table and interfere with data results. 
Table 1. Sentiment overview

\begin{tabular}{|c|c|c|}
\hline Sentiment & Defined Concept & Example Keywords and Associated Terms \\
\hline Positive & Users are enthusiastic, happy, or excited & $\begin{array}{l}\text { Happy, Love, Peace, Peaceful, Proud Unity, } \\
\text { Respect, Support }\end{array}$ \\
\hline Negative & Users are angry, annoyed, or frustrated & $\begin{array}{l}\text { Abandon, Abduction, Abolish, Brutality, } \\
\text { Hate, Murder, Racist, Slave }\end{array}$ \\
\hline
\end{tabular}

\section{Results}

Data was manipulated in several ways to show sentiment on Twitter regarding BLM during the summer of 2020. Visualizations were created in the forms of word clouds, keyword analysis, overall sentiment analysis, frequency changes, and correlation matrices. These visualizations helped show how different events affected thinking and provided additional insight into the public's views.

\subsection{Word Clouds}

In an effort to determine public opinion and sentiment on the topic, terms were collected and put into word clouds as seen in Figures 2 and 3. Although the tone was different, the terms were similar. Despite political opinion and sentiment towards the issue, this visualization shows the core of BLM is this question of support, racism, and coming together as one. Both sides wanted the same thing however, they view BLM in entirely different lights.

Although there was no definitive sentiment of the public using word clouds, positive is not defined as always supportive attitudes towards BLM, nor does all negative mean unsupportive attitudes, "positive" and "negative" are the emotional state of people who tweeted issues around BLM and there were different calls to action from the public over time regarding BLM as seen in the following data visualizations. At the beginning of the summer, there was a push towards love and coming together in addition to justice for police officers' crimes. As time passed, there was a shift towards raising funds and showing support through donations. By the end of the summer, the need for justice came back after the incident with Jacob Blake and there was a push for legal action.

\section{positive}

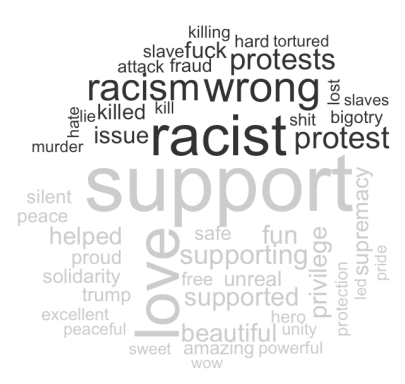

Figure 2. Positive sentiment 


\section{negative}

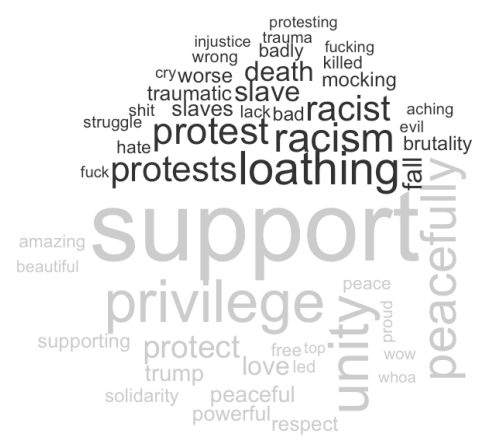

Figure 3. Negative sentiment

\subsection{Keyword Analysis}

The first finding to note is that throughout the summer, the most common words used in tweets surrounding BLM rarely changed over time. By grouping words, it is easier to understand different thoughts people had during the analyzed time and the different patterns and trends can be seen. As seen in Figures 4-6, common terms included words like "police", "lives, and "people". Over time, terms and phrases like "Defund the Police" and "Justice for Jacob Blake" began appearing as those topics became top of mind. As different events over the summer unfolded, the public maintained an interest in BLM but their calls for action shifted.

At the beginning of the summer, there was a push towards love and coming together in addition to justice for police officers' crimes. As time passed, there was a shift towards raising funds and showing support through donations. By the end of the summer, the need for justice came back after the incident with Jacob Blake and there was a push for legal action explaining the use of "justice".

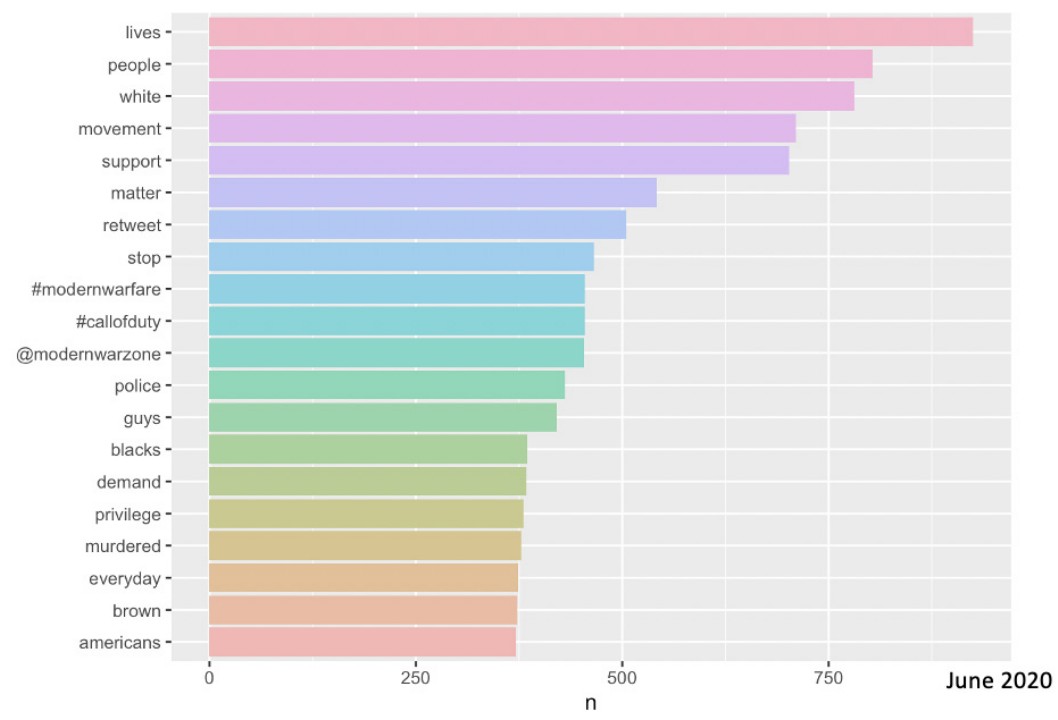

Figure 4. June 2020 keyword analysis 


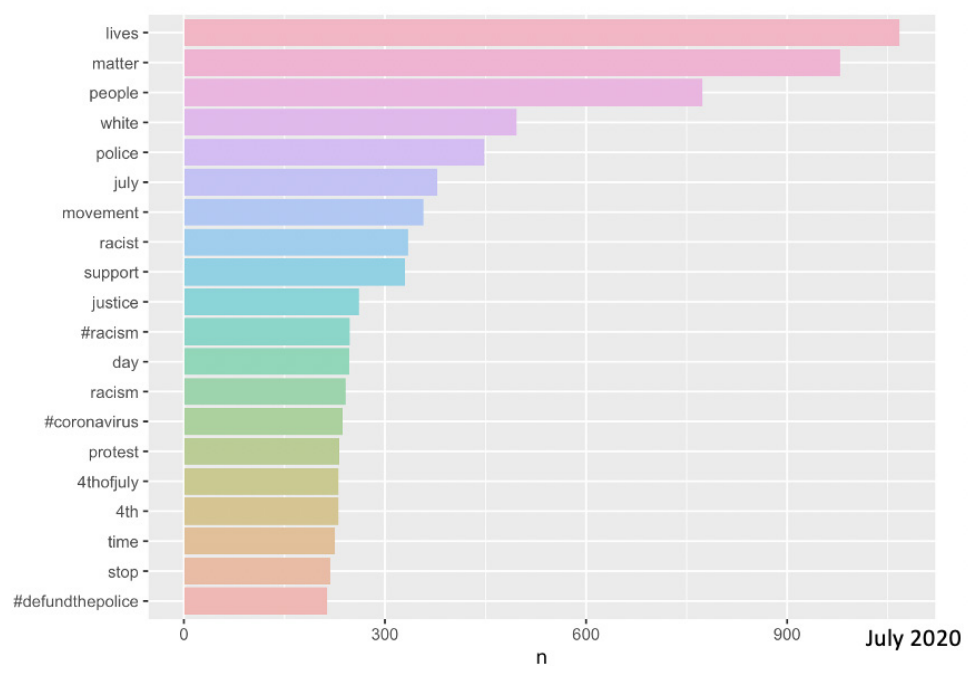

Figure 5. July 2020 keyword analysis

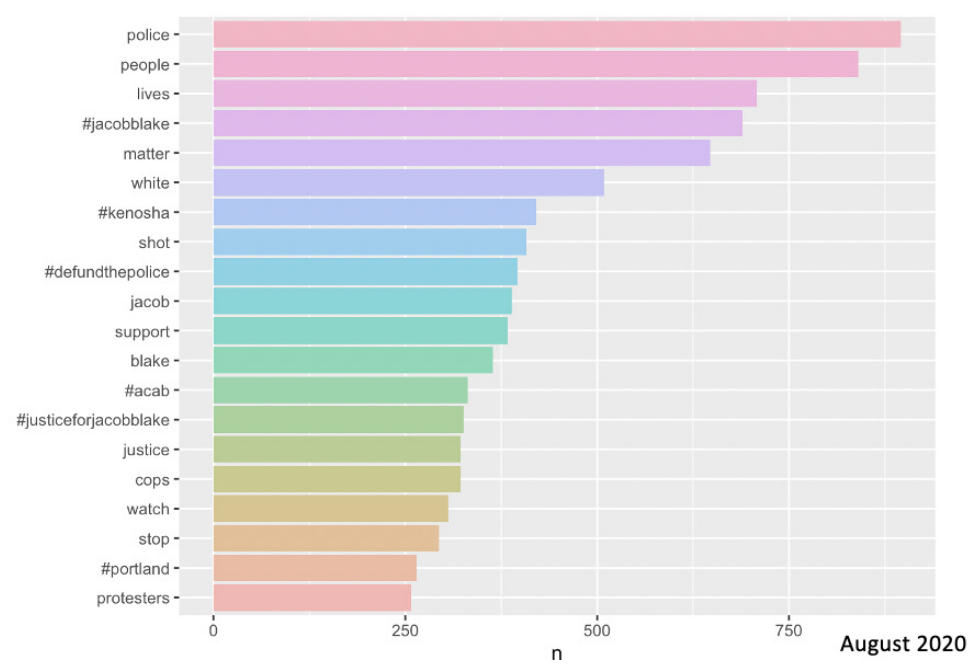

Figure 6. August 2020 keyword analysis

Considering BLM events and the sentiment analysis of the data, it can be seen in Figure 7 that the number of tweets mentioning the word "police" was most used at the beginning of June and again at the end of August in Figure 8. This can be associated with the increase in tweets mentioning \#BlackLivesMatter following George Floyd's death on May 25, 2020, and from the shooting of Jacob Blake on August 23, 2020. 


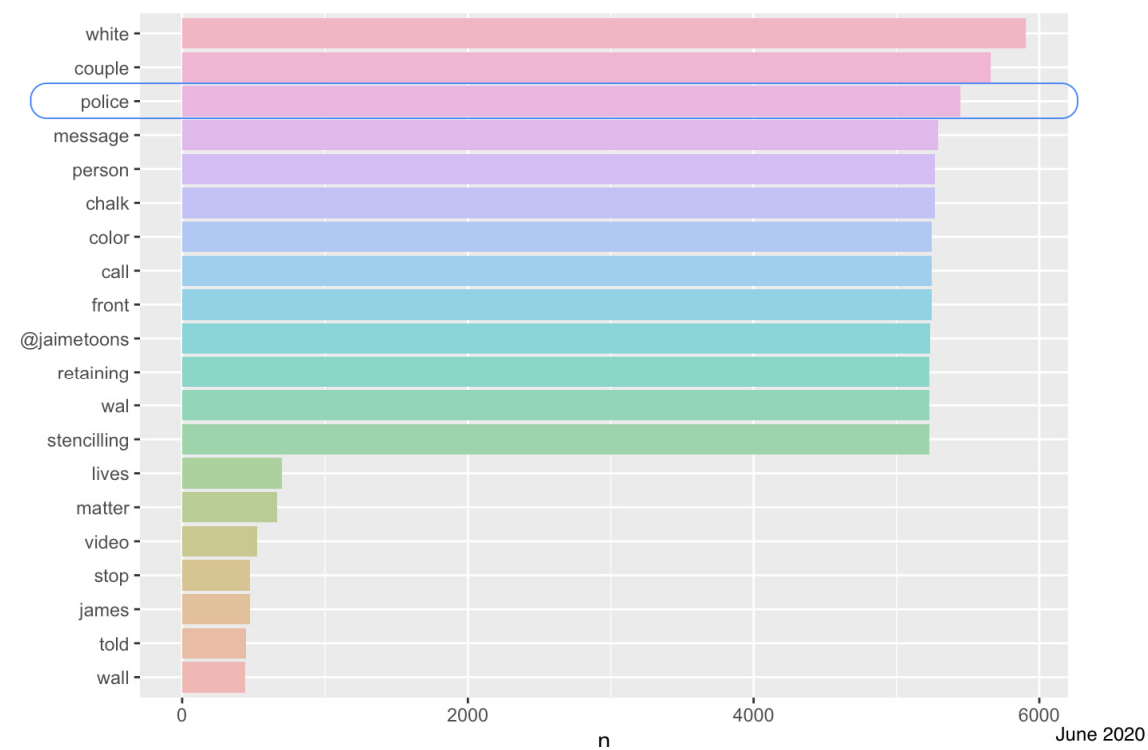

Figure 7. Early June keyword analysis

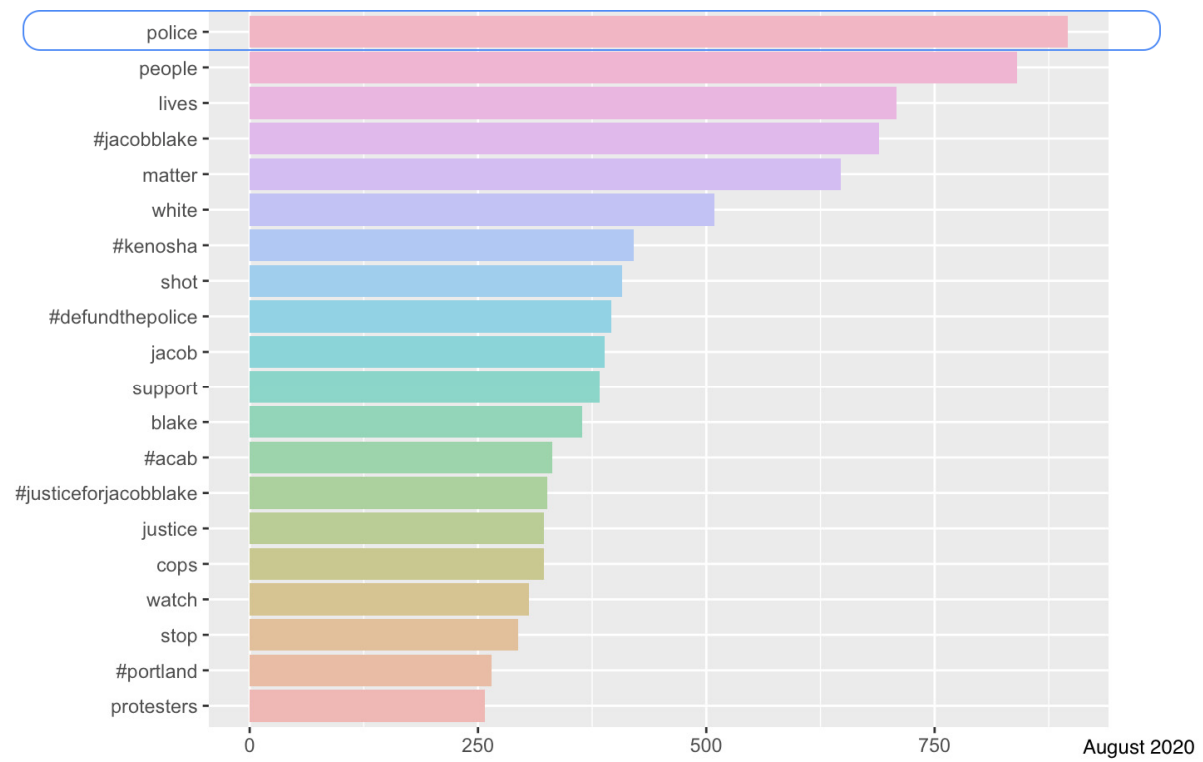

Figure 8. Late August keyword analysis

The terms "lives", "matter", "people", and "police" were consistently being used throughout July as seen in Figure 9 and again in August as seen in Figure 10. This shows how even though months had gone by, the main issues related to BLM had not changed. 


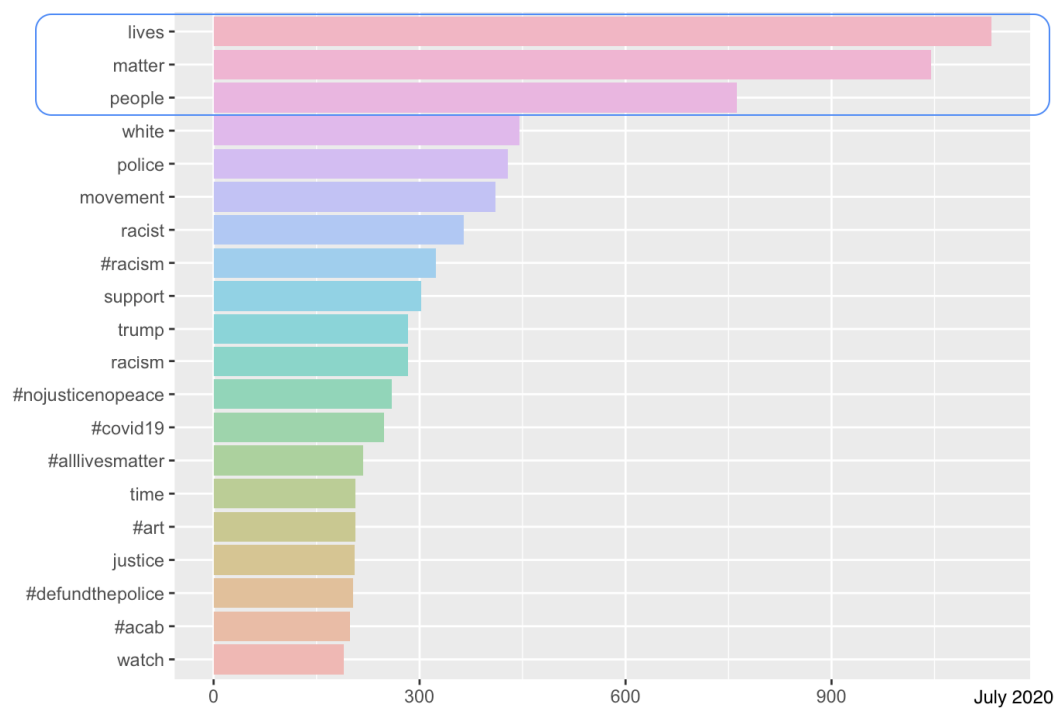

Figure 9. Most used word analysis in July

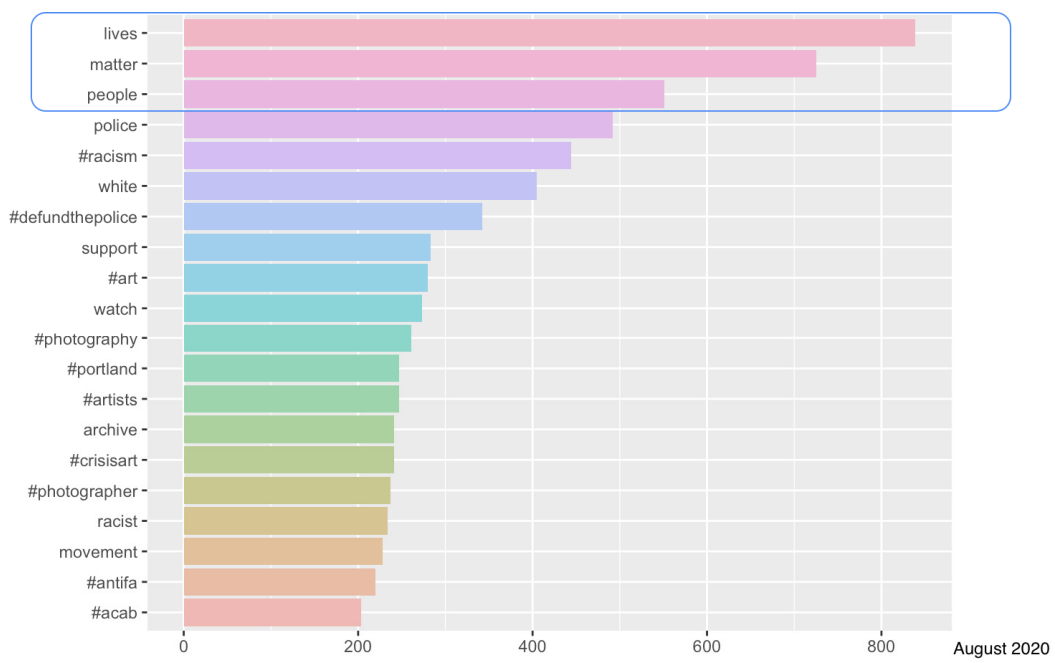

Figure 10. Most used word analysis in August

\subsection{Sentiment Analysis}

Figures 11, 12, and 13 analyze the contribution of each word towards the overall sentiment of BLM-related tweets throughout the summer of 2020. For the words contributing to the negative sentiment, the most used words were "racism", "racist", "protest", and "killed". For positive sentiment, the words contributing most to the overall tone were "support" and "love".

The visualization in Figure 11 showcases Twitter sentiment in June 2020. In the first week of June, Floyd's death was deemed a homicide which sparked protests across the country which can be seen in the usage of the terms "racism" and "protest". Given how upset people were, these terms contributed to the negative sentiment. In response, President Trump discussed deploying the military to curb protests. This tension would account for the increased usage of the word "loathing". At the beginning of Summer 2020, the death of George Floyd led to overflowing support to black people against racism on social media, which can explain the usage of words "support" and "unity" contributing to the positive sentiment. Also, people came together against the notion of "white privilege" which relates to the usage of the word "privilege". 


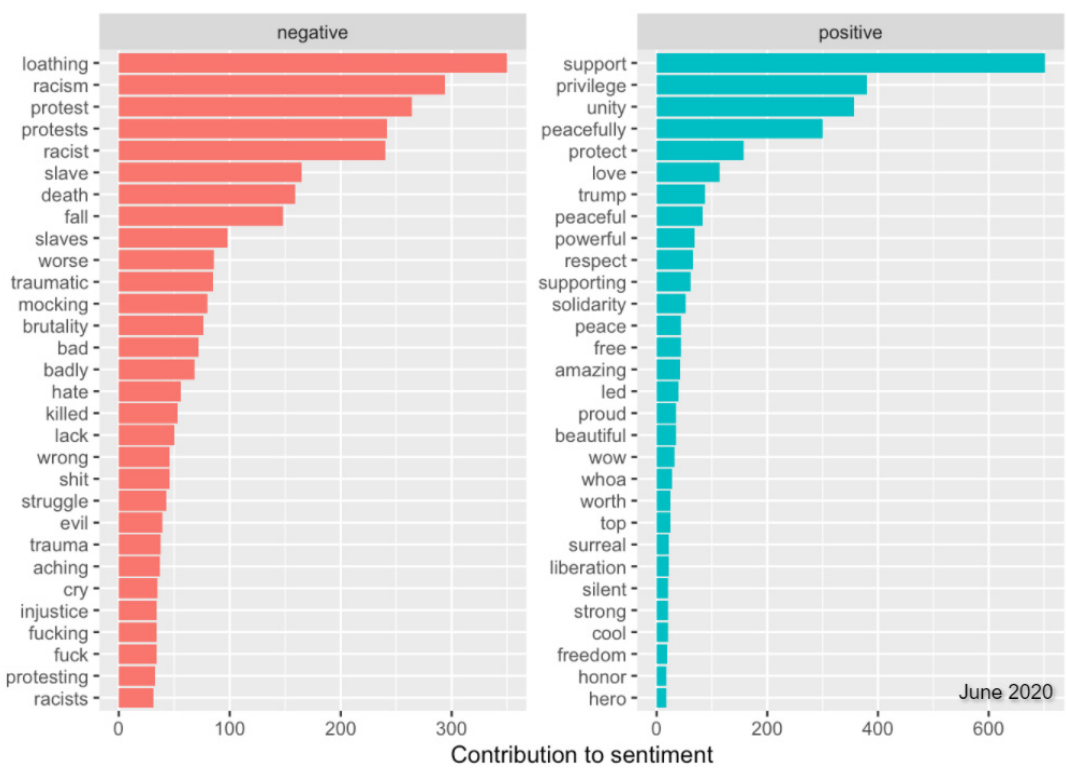

Figure 11. June sentiment

Figure 12 analyzes words contributing to sentiment in July 2020. It can be seen that the words contributing to the negative sentiment still majorly revolved around "racism" and "protest", which shows the death of George Floyd had a lasting effect on people and their view of BLM. As the summer progressed, there was a trend towards raising funds for the movement as well as supporting black-owned businesses which are illustrated in the usage of terms like "support" and "love" contributing to positive sentiment. Also, there was a sense of hope among people that the movement had paved a way to fight against the injustice against blacks by police officers which explain the usage of terms "happy" and "love" contributing to positive sentiment.

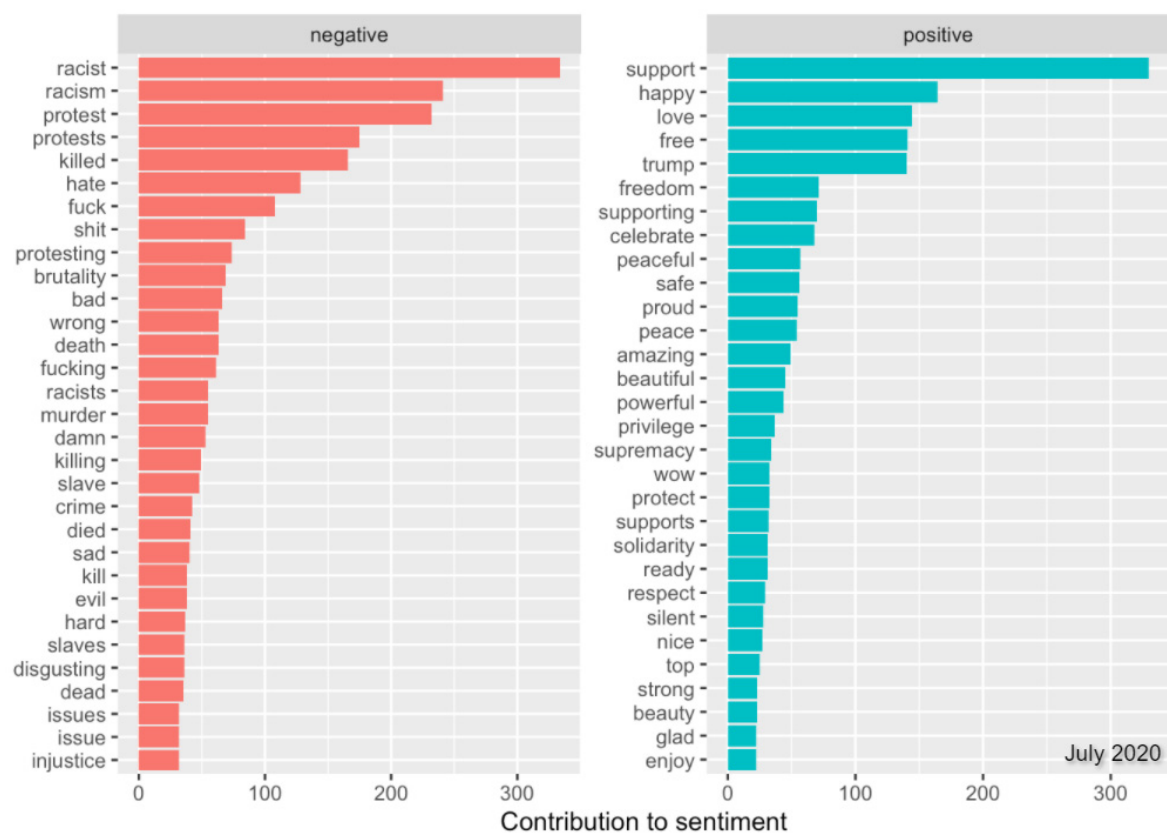

Figure 12. July sentiment

Figure 13 showcases terms adding to positive and negative sentiment in August 2020. In the summer of 2020, more than 10600 BLM protest events were held in the United States implying people were upset and wanted their voices heard. This frustration can account for the usage of the terms like "racism" and "protest" having a 
negative sentiment. At the end of the summer, the shooting of Jacob Blake in August led to outrage among people which in-turn contributed to several protests which explain the higher usage of terms "protest" and "protests". Several professional sports teams including NBA and MLB teams went on strike in protest, refusing to play their scheduled games which explains the usage of "support" regarding the contribution to the positive sentiment. In response to Blake's death, then-President Donald Trump reached out to Blake's family to meet which explains the usage of "trump" contributing to the positive sentiment.

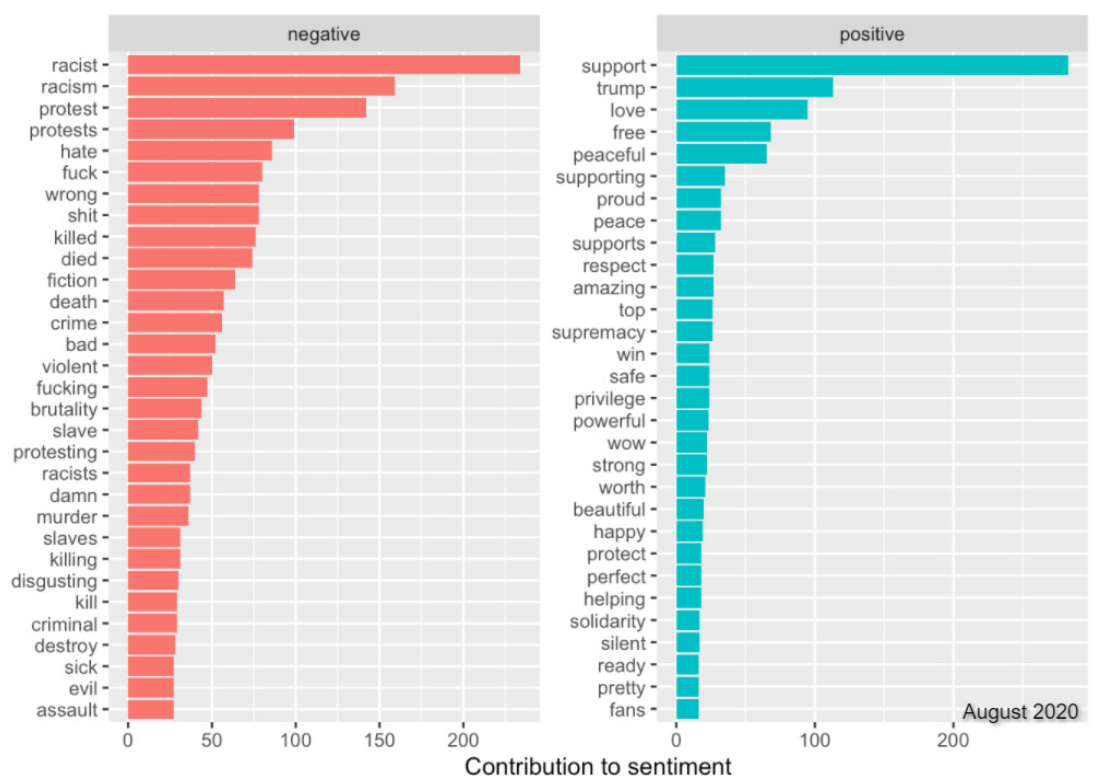

Figure 13. August sentiment

\subsection{Frequency Changes}

As the events of summer 2020 wore on, there was a call for action. People felt the government was not doing everything they could so a call to defund the police was made. Based on Figure 14, defunding the police was not a popular topic at the beginning of the summer. Either it was not being brought up or, the idea had not gained enough popularity to be talked about in mainstream media. As the months went on, the call was greater as was the opposition to the idea which explains the significant uptick of mentions.

In Figure 14, there is an increase of tweets regarding "Defund the police" throughout the summer. Between July and August, there is a sharp increase in the defunding topic. Although there was no specific event that increase could be attributed to, one could infer that the increase of BLM coverage in the media and on social networks caused people to have discussions on the topic. With increases in conversation, especially on a controversial viewpoint, it can be expected that both sides of the topic would have a lot to say. 


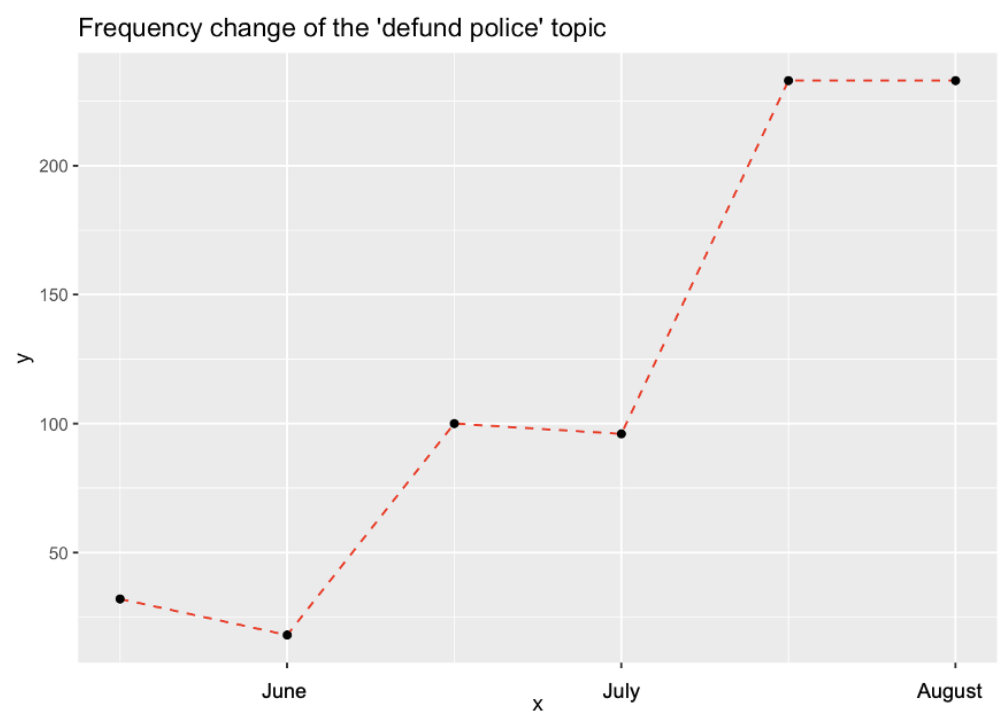

Figure 14. Defund the Police Frequency Change

One of the most interesting data points is that of voting. Figure 15 shows a marked increase between June and July. During this time there were calls for action and it can be inferred that the events of the summer inspired more and more people to get involved in the legislative process by voting. Regardless of opinion on BLM, the call for change, no matter the side, was there. So much so that the 2020 election had record voter turnout (Rabinowitz \& Schaul, 2020).

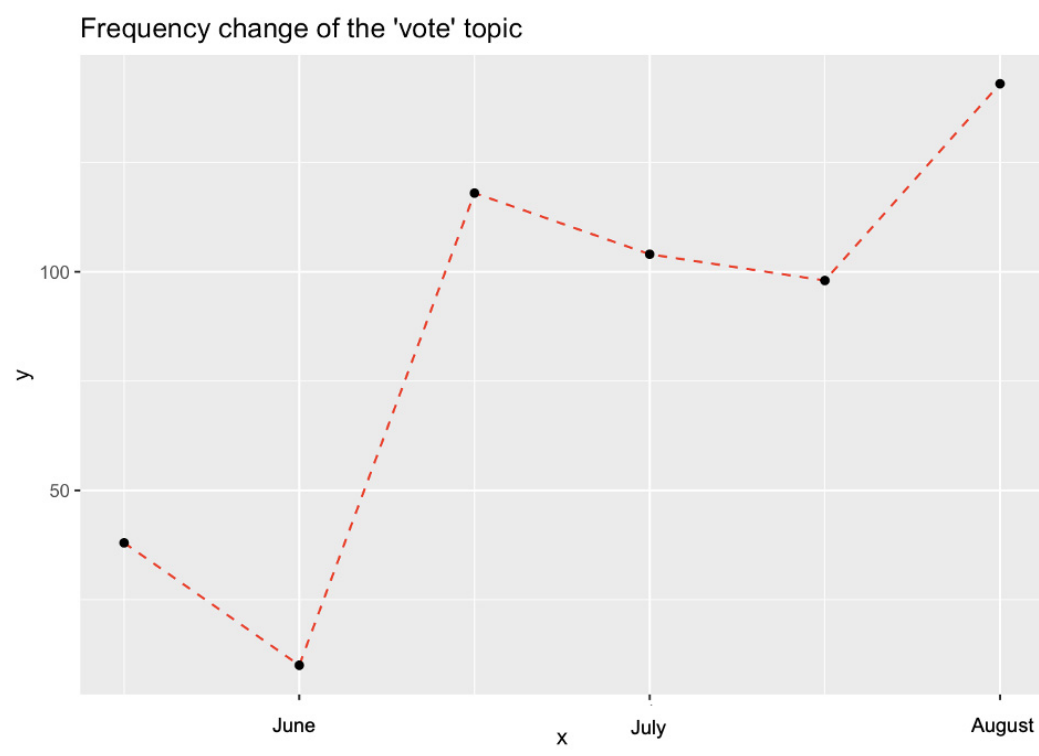

Figure 15. Voting Frequency Change

\subsection{Correlation Matrix Using Networks}

Correlation matrices help clarify items within the dataset. The correlation plots of words show the interaction between different terms. Linkages that are thick and light indicate a large number of occurrences where words were used together. The June correlation matrix, Figure 16, linked the words "matter", "james", "retaining", "lives", "stop", "justice" and "video" together. This can be attributed to George Floyd's death being captured on video, shared on social media, and sparking conversations all over the world about police brutality. Another set 
of linked words were "police", "person" and "white". This refers to the idea that white police officers are more likely to harm a black person rather than a white person when out in the field. People also tweeted about other events including pro-BLM art as seen by the terms "Jamie", "chalk" and "stenciling". A white couple had called the police after a black man, Jamie, stenciled a BLM chalk message on his front retaining wall. The couple's decision to call the police made mainstream news and sparked conversations on Twitter.

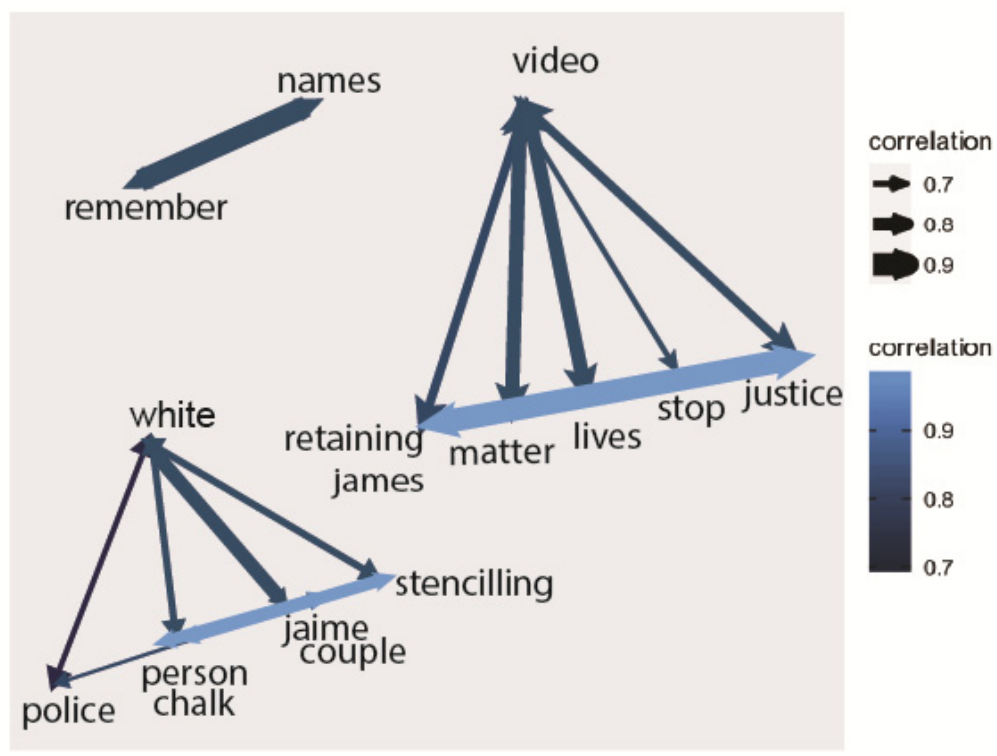

Figure 16. June Correlation Matrix

Figure 17 showcases several popular topics in August 2020. In August 2020, there were a high number of tweets discussing Joe Biden and Kamala Harris. Given the ramp-up to the 2020 election, there were discussions about their campaign as well as policy. This can relate to the increase in voter discussion as seen in the previous set of visualizations. There was also discussion associated with dissidents who are opposed to the police and generated protests seen in tweets saying ACAB ("All Cops Are Bastards") and defunding the police. At this point in the summer, there were several events regarding BLM and there was marked frustration. The movement even had an impact on artists and many of them defended it saying, "When words can't be spoken, art is there". People wanted justice for what happened, and it became clear that voting was the way to make that happen.

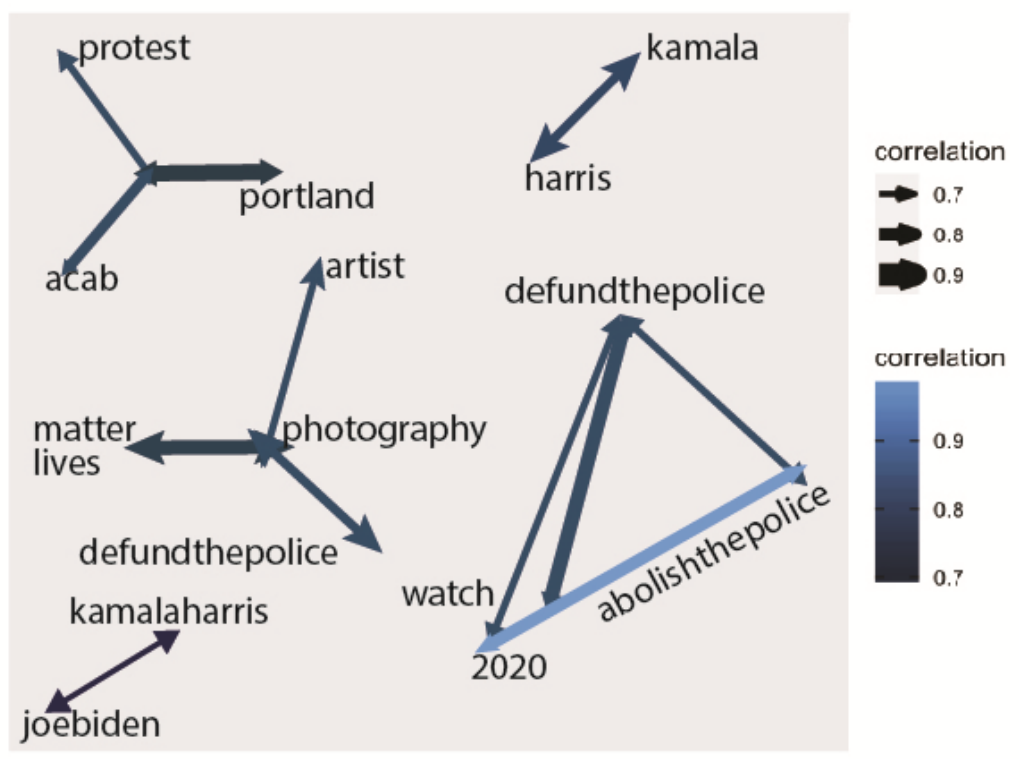

Figure 17. August Correlation Matrix 


\section{Discussion}

BLM has had a lasting effect on the way the public discusses issues of race in America. The movement's popularity and mission have inspired people to take a stand in their own way as seen with artists across the country. Also, protests put political pressure on legislators to make a difference which led to major impacts on legislation and political activism. BLM has undoubtedly changed the dynamic of modern society in terms of systemic racism. While it is impossible to truly and effectively quantify how many discriminatory acts have been prevented by BLM, the true value of the movement lies in the newfound conversations on an issue that has been ingrained in society's fabric.

\subsection{Black Lives Matter Movement Impact on Artists}

BLM has impacted artists across the country and the world and pushed artists to respond with paintbrushes and acrylics, cameras and film, ink and paper. Some of the most prominent artistic demonstrations of 2020 and 2021 were created in response to the incidents which occurred over Summer 2020. Such works included but were not limited to "Say Their Names", a piece using cutouts of faces and names of black Americans whose lives were taken at the hands of law enforcement, and an immersive experience created by Shawn Dunwoody and volunteers in New York City at Martin Luther King Jr. Park (Whittaker, Vaughn-Hall, Hood, Schuhmacher \& Jordan, 2020). Dunwoody had the amphitheater in the park painted black so visitors could write BLM-related messages (Whittaker et al., 2020). When people found themselves at a loss for words, art gave an outlet to convey a unique view and feeling on BLM. This level of expression made it easier to convey sentiment and spark conversations especially during a time where in-person communication was restricted due to COVID- 19 . Conversations online inspired these artists to showcase their point of view, give their reasons why, and spark thought among viewers.

\subsection{Impact on Legislation}

BLM was not just about protests and showing support through social media, it was to highlight the need to change law enforcement and criminal justice policies. In June, the Minneapolis City Council voted to advance a proposal that would create a new Department of Community Safety and Violence Prevention aimed to reduce the powers of the Police Department (Navratil, 2020). In New York City, Mayor Bill de Blasio pledged to cut funding to the New York Police Department and announced his support for repealing a state law that makes police disciplinary records confidential (Navratil, 2020). In response to the death of Breonna Taylor, Louisville's Metro Council voted to advance "Breonna's law" which would limit the use of no-knock warrants (Hauser, 2020). Finally, the BREATHE Act, named for Eric Garner and George Floyd, aims to redirect federal funds away from police, prisons, and other branches of the criminal justice system and into underserved communities of color (King, 2020). BLM's impact reached far beyond social media and into legislation that created meaningful changes.

\subsection{Online Conversation and Voting}

BLM did more than just spark conversations on Twitter over Summer 2020. People were frustrated and angry with how racism has been handled in America as seen in the data regarding sentiment. There were calls for change and many activists, on both sides of the issue, began working in their communities to invigorate people to use their emotions in the voting booth. Black voters, in particular, rallied at the polls and according to some, changed the course of the election. Georgia, a notoriously red state with a high African American population, flipped blue for the first time since 1992 not only electing Joe Biden as president but also two democrat senators (The New York Times, 2021). Despite bringing like-minded groups together on Twitter, BLM highlighted just how different both sides viewed the issue. One stark example was seen in the Capitol Riots in January 2021 when compared to BLM protests during summer 2020. Although the investigation is still pending regarding the Capitol Riots, many people on Twitter could not help but notice the difference in treatment when it came to black Americans protesting when compared to white. Some tweeting photos of National Guardsmen in full riot gear during BLM protests juxtaposed next to photos of Capitol police taking photos with protestors (Watson, 2021). The division of the country, especially regarding race will be an issue for years to come. However, by using tools like sentiment analysis and term frequency it can be easier to understand what the key issues are on both sides and what the proposed solutions are.

\subsection{Research Limitations}

One limitation of this research is that the focus was on the overall sentiment of a tweet. Meaning, that although tone could be identified, the opinion conveyed in the tweet was not. In the future, it could be helpful to know 
which side of the issue a tweet fell as well as its overall sentiment so that there can be a better understanding of the public's opinion regarding BLM.

\section{References}

Anderson, M., Barthel, M., Perrin, A., \& Vogels, E. (2020, August 28). \#BlackLivesMatter surges on Twitter after George Floyd's death. Retrieved December 22, 2020, from https://www.pewresearch.org/fact-tank/2020/06/10/blacklivesmatter-surges-on-twitter-after-george-floydsdeath/

Andrew, S. (2020, June 17). There's a growing call to defund the police. Here's what it means. CNN. Retrieved from https://www.cnn.com/2020/06/06/us/what-is-defund-police-trnd/index.html

BBC News. (2020, July 16). George Floyd: What happened in the final moments of his life. BBC News. Retrieved from https://www.bbc.com/news/world-us-canada-52861726

Beckman, L. (2020). \#BlackLivesMatter saw tremendous growth on social media. Now what? Mashable. Retrieved

from https://sea.mashable.com/social-good/11349/blacklivesmatter-saw-tremendous-growth-on-social-media-no w-what

Buchanan, L., Bui, Q., \& Patel, J. (2020, July 03). Black Lives Matter May Be the Largest Movement in U.S. History. $\quad$ Retrieved December $14, \quad 2020, \quad$ from https://www.nytimes.com/interactive/2020/07/03/us/george-floyd-protests-crowd-size.html

Carney, N. (2016). All Lives Matter, but so Does Race. Humanity \& Society, 40(2), 180-199.

Dimock, M., \& Wike, R. (2020, November 13). America is exceptional in the nature of its political divide. Pew Research Center. Retrieved from https://www.pewresearch.org/fact-tank/2020/11/13/america-is-exceptional-in-the-nature-of-its-political-divi $\mathrm{de} /$

Garza, A. (2018, December 07). A herstory of the \#BlackLivesMatter Movement. Retrieved February 02, 2021, from https://www.nfg.org/news/herstory-blacklivesmatter-movement

Haffner, M. (2018). A place-based analysis of \#BlackLivesMatter and counter-protest content on Twitter. GeoJournal, 84(5), 1257-1280.

Hauser, C. (2020). New Breonna Taylor Law Will Ban No-Knock Warrants in Louisville, Ky. Retrieved from https://www.nytimes.com/2020/06/12/us/breonna-taylor-law-passed.html

King, M. (2020). Black Lives Matter goes big on policy agenda. Politico. Retrieved from https://www.politico.com/news/2020/08/28/black-lives-matter-breathe-act-403905

Lardieri, A. (2020, June). Starbucks Prohibits Employees From Wearing Clothes Supporting Black Lives Matter

[Editorial]. U.S. News. Retrieved from https://www.usnews.com/news/politics/articles/2020-06-11/starbucks-prohibits-employees-from-wearing-cl othes-supporting-black-lives-matter

Morales, C. (2020, November 7). What We Know About the Shooting of Jacob Blake. The New York Times. Retrieved from https://www.nytimes.com/article/jacob-blake-shooting-kenosha.html.

Mundt, M., Ross, K., \& Burnett, C. M. (2018). Scaling Social Movements Through Social Media: The Case of Black Lives Matter. Social Media + Society, 4(4), 205630511880791.

Navratil, L. (2020, June). Minneapolis City Council votes unanimously for proposal that could replace Police Department.

Retrieved from https://www.startribune.com/minneapolis-city-council-votes-unanimously-for-proposal-that-could-replacepolice-department/571504662/

Oppel, R. A., Taylor, D. B., \& Bogel-Burroughs, N. (2020, December 29). What to Know About Breonna Taylor's Death. Retrieved December 30, 2020, from https://www.nytimes.com/article/breonna-taylor-police.html

Pew Research Center. (2020, June 10). Use of the \#BlackLivesMatter hashtag hits recordlevels amid global protests over George Floyd's death while in police custody. Pew Research Center. Retrieved from https://www.pewresearch.org/fact-tank/2020/06/10/blacklivesmatter-surges-on-twitter-after-george-floydsdeath/ft_2020-06-10_blm_01_new/ 
Rabinowitz, K., \& Schaul, K. (2020, December 8). 2020 turnout is the highest in over a century. The Washington Post. Retrieved from https://www.washingtonpost.com/graphics/2020/elections/voter-turnout/

The New York Times. (2020, September 8). What We Know About the Death of George Floydin Minneapolis. Retrieved from https://www.nytimes.com/article/george-floyd.html

The New York Times. (2021, January 5). Georgia Election Results. The New York Times. Retrieved from https://www.nytimes.com/interactive/2020/11/03/us/elections/results-georgia.html

Watson, J. (2021, January 15). Comparison between Capitol siege, BLM protests is denounced. AP NEWS. Retrieved

from

https://apnews.com/article/donald-trump-capitol-siege-race-and-ethnicity-violence-racial-injustice-afd7dc21 65f355a3e6dc4e9418019eb5

Whittaker, C. E., Vaughn-Hall, J., Hood, M., Schuhmacher, T., \& Jordan, C. (2020, October 08). Black Lives Matter movement has impact on artists - and they have our attention. Courier Post. Retrieved Feb. 3, 2021, from https://www.courierpostonline.com/story/life/2020/10/08/black-lives-matter-movement-artists-inspiration-n ew-jersey-new-york-philadelphia/3495958001/

Wijers, I., Akkermans, M., Malsen, E., Berndsen, J., \& Gerards, C. (2017, September 26). Black Lives Matter too: From \#hashtag to movement. Retrieved December 08, 2020, from https://www.diggitmagazine.com/papers/black-lives-matter-too-hashtag-movement

\section{Copyrights}

Copyright for this article is retained by the author, with first publication rights granted to the journal.

This is an open-access article distributed under the terms and conditions of the Creative Commons Attribution license (http://creativecommons.org/licenses/by/4.0/). 